\title{
A PREPARAÇÃO DE ALUNOS PARA MOOT COURTS: A CRIAÇÃO DE UMA CULTURA DE VALORIZAÇÃO ÀS COMPETIÇÕES DE JULGAMENTOS SIMULADOS E SEUS BENEFÍCIOS
}

\author{
PREPARING STUDENTS FOR MOOT COURTS: THE \\ DEVELOPMENT OF A CULTURE THAT VALUES MOCK TRIALS \\ AND ITS ENTAILED BENEFITS
}

ADRIANA LACOMBE COIRO ${ }^{1}$

\begin{abstract}
ReSumO: Moot Courts existem há anos. São julgamentos simulados internacionais, em que é publicado um caso hipotético e equipes de alunos apresentam peças escritas e defesas orais de cada parte, competindo com outras universidades Tradicionais nos Estados Unidos e em alguns países da América Latina, os moot courts são relativamente novos no Brasil, onde são poucas as universidades que desenvolveram uma tradição de valorização e incentivo à participação dos alunos nestas competições. Este artigo se destina a auxiliar alunos e professores na criação desta cultura, e a expor os benefícios que a prática de moot courts pode trazer aos alunos. $\mathrm{O}$ conhecimento da competição, a seleção dos alunos, a atuação do orientador da equipe, o financiamento e a ajuda externa são alguns dos pontos abordados, bem como a criação de um curso preparatório para o desenvolvimento de habilidades que serão necessárias aos alunos nas competições, e posteriormente valorizadas no ambiente profissional. Através do compartilhamento de práticas adotadas, espera-se contribuir com o desenvolvimento da cultura de moot courts no Brasil, ajudando alunos e coaches interessados no tema, bem como demonstrando os benefícios que advém desta prática para os futuros advogados.
\end{abstract}

PAlavRAs-Chave: Julgamentos simulados; Competições internacionais; Simulações; Memoriais; Oradores.

\footnotetext{
${ }^{1}$ Bacharel em direito pela FGV Direito Rio. Advogada. Orientadora de equipes semi-finalistas na Inter American Moot Court Competition (2011, 2015), juíza da FGV Moot Court Competition (2014, 2015), orientadora de equipe na IX Competição Internacional Victor Carlos Moreno- TPI- (2012), participante da Inter American Moot Court Competition (2009). E-mail: adricoiro@gmail.com.
} 
ABSTRACT: Moot Courts have been around for years. They consist of international mock trials, in which a hypothetical case is published and teams of students present written and oral arguments for opposite sides, competing against other universities. Common in the United States and in some Latin American countries, moot courts are relatively new in Brazil, where few universities have developed the tradition of encouraging students to participate in these competitions. This article aims to assist students and teachers to create a culture that values moot courts, and to explore the benefits that this practice can bring to students. Knowledge of the competition, student selection, team coaching, funding and external assistance are some of the issues addressed, as well as the creation of a preparatory course for the development of the skills that will be necessary not only for students in competitions, but also later on for law professionals. Through shared practices, it hopes to contribute to the development of a culture that values these mock trials, guiding students and coaches interested in the subject, and demonstrating the benefits of this practice for future lawyers.

KEYWORDS: Moot courts; Mock trials; International competition; Briefs; Oral rounds.

\section{ANTES DE MAIS NADA: CONHECER A COMPETIÇÃO}

O primeiro passo para qualquer experiência acadêmica que envolva a participação em moot courts é evidente: conhecer a competição. Seja para professores de matérias preparatórias, para orientadores ou para participantes, o conhecimento da estrutura da competição é o ponto de partida essencial, a começar pelo tribunal perante o qual o julgamento estará sendo simulado, e, por conseguinte, sua competência material. Há, atualmente, uma série de competições existentes, com foco em áreas jurídicas diversas. É preciso, então, ter um conhecimento mínimo sobre o tipo de julgamento ao qual os alunos serão expostos, para possibilitar um treinamento anterior à divulgação do caso daquela competição. Se todos os envolvidos já possuírem um amplo grau de conhecimento sobre o funcionamento daquele tribunal, a partir da publicação do caso a preparação dos alunos poderá se dedicar exclusivamente ao caso concreto. Sem esse conhecimento, por outro lado, algumas reuniões precisarão ser dedicadas à aprendizagem do sistema.

Além do conhecimento material, é indispensável, também, o conhecimento formal da competição. Quais as regras específicas daquela simulação? Em que língua devem ser apresentados os textos e sustentados os argumentos? Quais são os critérios adotados para a avaliação dos participantes nas etapas escrita e oral? Qual o peso proporcional de cada etapa? Sem responder a essas perguntas, há equipes, por exemplo, que se dedicam quase exclusivamente à preparação para etapa oral, deixando os memoriais escritos em segundo plano. Contudo, há competições em que 
ambas as etapas possuem o mesmo peso para a nota final dos participantes. Na etapa escrita, especialmente, a atenção a regras formais é essencial, pois estas costumam requerer preocupação com detalhes que podem parecer triviais, tais como a formatação do material a ser submetido, ou o número de máximo de páginas dos memoriais, mas que, se deixadas para o último momento, podem custar pontos preciosos na avaliação, prejudicando o árduo trabalho dos alunos.

Já na etapa oral, deve-se considerar, além dos critérios de avaliação, dois outros pontos essenciais. Primeiro: se cada equipe puder falar em sua língua materna, há tradução simultânea? A resposta positiva deve ser considerada no momento da preparação dos alunos, uma vez que, em rodadas traduzidas, a velocidade da fala deve ser outra. De nada adianta explicar rápida e eficientemente argumentos cuidadosamente preparados, para perdê-los na tradução. É por isso que muitas vezes rodadas traduzidas preveem um tempo maior de exposição do que rodadas realizadas na mesma língua, e os alunos devem programar sua fala de acordo com esse detalhe.

O segundo ponto a ser considerado desde o início dos preparativos para a rodada oral são os avaliadores, os juízes daquela competição. Em competições anteriores, quem foram os juízes participantes? O campo de atuação, o conhecimento que os juízes possuem sobre o tema discutido, sua especialidade e mesmo sua nacionalidade são informações importantes. Participantes de culturas diferentes se preocupam com formas diversas de argumentação, avaliam questões distintas. Enquanto um juiz colombiano, ex-participante daquela competição, avaliará o conhecimento da jurisprudência de determinado tribunal demonstrado pelo aluno, o número de casos citados por ele, e ficará bem impressionado com uma argumentação objetiva, um juiz norte-americano pode avaliar melhor uma apresentação em que a lógica e o dinamismo argumentativo superem o uso em quantidade de precedentes, em que se priorize a seleção de poucos casos relevantes, a estrutura do raciocínio e a oratória do competidor.

Por último, há ainda uma questão fundamental, e que deve sempre ser ressaltada aos alunos: a existência de fatores externos ao controle da competição. Ao avaliar a apresentação de uma dupla ou um grupo de alunos o juiz irá, mesmo que de forma inconsciente, compará-los às demais apresentações ouvidas naquele dia. Se esta é a quarta rodada em que o juiz está atuando naquela tarde, os mesmos argumentos já ouvidos nas rodadas anteriores terão um impacto menor. Se a equipe representando o papel contrário estiver bem preparada, possibilitando discussões de alto nível, isso pode elevar as notas de ambas as equipes. São fatores que dependem, ao final, da sorte, do acaso. Fatores incontroláveis, e não determinantes, mas que não podem ser completamente ignorados.

\section{A SELEÇÃO DOS ALUNOS}

Conhecendo-se bem a competição, passa-se ao segundo passo: a seleção dos alunos, que deve começar muito antes da competição daquele ano. Isto porque a possibilidade de selecionar bons alunos interessados, ano após ano, está diretamente relacionada à criação de uma cultura de moot courts na universidade. Trata-se de um processo cíclico: 
quanto mais se investe em competições de moot court - e investimento, aqui, não só de recursos financeiros, mas de tempo, de equipe, de professores e alunos envolvidos nas competições - melhores serão os resultados de uma equipe. Quanto melhores os resultados de uma equipe, mais felizes voltam os competidores, mais divulgado é o sucesso dos participantes, o que acaba por promover a competição. Como consequência, haverá cada vez mais alunos interessados em participar nos próximos anos. A formação de uma cultura de valorização do moot, construída ao longo de anos, é assim essencial para que um número cada vez maior de alunos se interesse pelo tema.

Formado um bom grupo de interessados, algumas práticas podem ser adotadas para que a seleção busque os melhores alunos para aquela atividade, que terão o melhor desempenho. Mas como selecioná-los?

Primeiro, é importante escolher alunos que se candidatem pelos motivos certos, ou seja, que saibam que passarão os próximos meses imersos em pesquisa e treinamento, que estejam dispostos a abrir mão de feriados, finais de semana e algumas noites de sono, que se dedicarão à causa. Entrar em um moot com o único objetivo de passar uma semana viajando dificilmente trará bons resultados na competição. $\mathrm{O}$ interesse dos alunos nos temas da competição e o nível de dedicação que eles estão dispostos a oferecer podem ser avaliados, por exemplo, ao longo de um curso de preparação para os moots, como o descrito mais adiante.

Em segundo lugar, muito embora não se trate de regra - como todas as sugestões aqui propostas -, a seleção por equipes tende a conseguir melhores resultados do que a seleção individual. Isto porque são alunos que passarão meses trabalhando lado a lado, se criticando, se ajudando, aprendendo um com o outro. Dois participantes selecionados individualmente podem adquirir este espírito de equipe necessário, mas dois participantes que já passaram pelo processo seletivo juntos, em regra, terão maior disposição para trabalharem por tanto tempo como uma boa equipe.

Por último, a seleção dos alunos deve considerar tanto as habilidades escritas quanto as habilidades orais dos candidatos, simulando a redação de um memorial (ou parte dele) e de uma defesa oral, uma vez que ambas serão relevantes para um bom desempenho da equipe na competição. Esta é outra razão pela qual a seleção em duplas é interessante: alunos diferentes muitas vezes se complementam, e uma equipe que trabalha bem junta pode ser mais forte do que indivíduos com habilidades semelhantes.

\section{O TRABALHO DO COACH}

Escolhidas as equipes, deve-se focar no trabalho realizado entre elas e o coach, desde a publicação do caso hipotético até o dia da competição. É uma tarefa extremamente gratificante, mas que requer empenho.

A atuação do coach se assemelha, até certo ponto, a de um orientador de monografia: seu papel é direcionar os alunos, guiá-los, apontar os caminhos corretos, sem interferir no conteúdo do trabalho a ser desenvolvido. Na prática, no entanto, como muitas vezes os alunos participantes são mais novos, e as competições exigem tanto etapas escritas quanto etapas orais, o coach acaba por ter um papel ainda mais relevante, pois é ele quem propõe o ritmo a ser seguido. Meses antes da competição, 
quando tudo parece ainda muito distante, é com o incentivo e com as cobranças do coach que muitos alunos começam de fato a pesquisar, escrever, treinar. Com esse objetivo, uma reunião semanal é essencial para que os alunos prestem contas do que fizeram até ali, tirem dúvidas. Nesses momentos, cabe ao coach auxiliar os competidores e direcionar os próximos passos das atividades.

Ex-participantes, em regra, se tornam excelentes coaches, prática comum em universidades que costumam participar das competições. São alunos e ex-alunos que conhecem bem a competição, que aprenderam com seus erros, que conhecem intimamente todas as etapas pelas quais passam os participantes. São, em geral, ótimas escolhas, devendo-se tomar apenas um cuidado: é preciso diferenciar as figuras do coach e dos participantes. Orientadores muito novos, que acabaram de participar de um moot podem acabar vendo a oportunidade de serem coaches como uma "segunda chance" de participar da competição, deixando de ter o distanciamento necessário para incentivar os alunos e direcioná-los, sem fazer o trabalho por eles.

É preciso, ainda, que o coach, assim como os alunos, esteja disposto a dedicar seu tempo ao projeto. É necessário ler e reler os argumentos das equipes, orientando sem interferir, ver e rever as sustentações orais, conseguir extrair o melhor de cada aluno, manter o equilíbrio de uma equipe - tarefas que requerem tempo.

Por fim, a figura do coach é importante para lembrar aos alunos o que está em jogo, e ensinar que o que importa não é, ao final, ser o vencedor da competição. É claro que ganhar é relevante, mas cabe ao coach também ressaltar tudo o mais que será ganho ao longo do processo: o aprendizado, os contatos, a experiência. Não deixar os participantes esquecerem, seja ao longo das preparações, seja após a divulgação dos resultados, que há muitas formas de ganhar além de voltar com o prêmio de melhor equipe para casa.

\section{A BUSCA POR FINANCIAMENTO}

Compostas as equipes, como bancá-las? O financiamento da participação de alunos em moot courts é também uma questão relevante, que não deve ser deixada em segundo plano. Dentro da prática de incentivo à criação de uma cultura de moots, o ideal é que a universidade possa, também, auxiliar financeiramente os alunos, uma vez que com frequência tratam-se competições internacionais, com gastos volumosos em passagem, acomodação e alimentação, e mesmo taxas de inscrição significativas.

O financiamento pela universidade não apenas possibilita a ida de alunos que em outras situações nunca poderiam passar por uma experiência semelhante, como mostra, de fato, um investimento da instituição naqueles alunos e a confiança que organização possui em seu potencial, o que ajuda a motivá-los.

Aqui a formação de uma cultura do moot courts volta a criar um ciclo virtuoso importante: quanto melhores os resultados de uma equipe, maiores serão os ganhos da universidade, que terá seu nome divulgado entre especialistas da área, universidades nacionais e estrangeiras, alunos em potencial. A boa divulgação, por sua vez, contribui para o interesse das instituições em patrocinar estas empreitadas no futuro, o que, por sua vez, levará a resultados melhores, e assim sucessivamente. 
Mas nem todo o financiamento dos alunos pode, ou deve, vir da universidade. É comum que se busque patrocínio de escritórios de advocacia, instituições não governamentais e advogados interessados no tema abordado pela competição. Nos últimos anos, a prática de crowdfunding (arrecadação de dinheiro através de pequenas doações coletadas em sites da internet) também tem obtido sucesso. Estas formas de arrecadação ajudam os participantes a se organizar desde cedo, reforçam o espírito de equipe ao se buscar atingir um objetivo comum, e incentivam, novamente, a dedicação dos alunos, que se empenham sabendo que muitos contribuíram para que eles pudessem desfrutar daquela experiência. E não é só para o financiamento que a ajuda externa tem papel importante. Ela é útil durante todo o preparo das equipes. Vejamos.

\section{A AJUdA EXTERnA}

Compostas as equipes, como bancá-las? O financiamento da participação de alunos em moot courts é também uma questão relevante, que não deve ser deixada em segundo plano. Dentro da prática de incentivo à criação de uma cultura de moots, o ideal é que a universidade possa, também, auxiliar financeiramente os alunos, uma vez que com frequência tratam-se competições internacionais, com gastos volumosos em passagem, acomodação e alimentação, e mesmo taxas de inscrição significativas.

O financiamento pela universidade não apenas possibilita a ida de alunos que em outras situações nunca poderiam passar por uma experiência semelhante, como mostra, de fato, um investimento da instituição naqueles alunos e a confiança que organização possui em seu potencial, o que ajuda a motivá-los.

Aqui a formação de uma cultura do moot courts volta a criar um ciclo virtuoso importante: quanto melhores os resultados de uma equipe, maiores serão os ganhos da universidade, que terá seu nome divulgado entre especialistas da área, universidades nacionais e estrangeiras, alunos em potencial. A boa divulgação, por sua vez, contribui para o interesse das instituições em patrocinar estas empreitadas no futuro, o que, por sua vez, levará a resultados melhores, e assim sucessivamente.

Mas nem todo o financiamento dos alunos pode, ou deve, vir da universidade. É comum que se busque patrocínio de escritórios de advocacia, instituições não governamentais e advogados interessados no tema abordado pela competição. Nos últimos anos, a prática de crowdfunding (arrecadação de dinheiro através de pequenas doações coletadas em sites da internet) também tem obtido sucesso. Estas formas de arrecadação ajudam os participantes a se organizar desde cedo, reforçam o espírito de equipe ao se buscar atingir um objetivo comum, e incentivam, novamente, a dedicação dos alunos, que se empenham sabendo que muitos contribuíram para que eles pudessem desfrutar daquela experiência. E não é só para o financiamento que a ajuda externa tem papel importante. Ela é útil durante todo o preparo das equipes. Vejamos.

\section{A AJUDA EXTERNA}

Para além do financiamento, a ajuda externa pode trazer grandes contribuições. Esse é um detalhe muitas vezes esquecido por equipes novas, ou por coaches menos experientes: a busca de auxílio apenas enriquece a experiência e o desempenho das equipes de moot court.

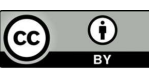


Ex-participantes e antigos coaches sabem o quanto as competições são importantes para os envolvidos, e na maior parte das vezes ficam felizes em poder contribuir. Professores e advogados especialistas na matéria podem ser valiosas fontes de ideias. Há sempre argumentos que não foram explorados, questões que não foram levantadas, que novos olhos podem ajudar a descobrir. Não se quer dizer, com isso, que os memoriais escritos devem ser feitos a dezenas de mãos. Mas tirar dúvidas e discutir casos que façam parte da jurisprudência internacional são exemplos desse tipo de colaboração. Advogados e professores também podem contribuir com excelentes dicas de oratória: nesse caso, fazer rodadas simuladas com bancas de voluntários é uma experiência que apenas enriquece o preparo e o aprendizado dos alunos.

Praticar com outras universidades também pode trazer ótimos resultados. A atividade é importante para ressaltar aos alunos que, quanto mais todos souberem, mais ganham, afinal, o objetivo não deve ser apenas ganhar dos demais. Treinar as rodadas orais com outras equipes que estão se preparando deixa claros os pontos que precisam ser melhorados, demonstra novos problemas a serem enfrentados e novas questões a serem analisadas no caso, o que, ao fim, ajuda a todos.

\section{A IMERSÃO DURANTE A COMPETIÇÃO}

Após tudo pronto, quando se chega ao local da competição, os momentos finais não devem ser desperdiçados. Os primeiros dias de uma competição, ou os últimos dias antes dela, já na cidade em que serão realizadas as rodadas orais, são ideais para praticar. É um momento em que é possível uma imersão completa no tema, nos argumentos preparados, já que os alunos e o coach estão afastados de suas vidas cotidianas e podem se dedicar integralmente à preparação, como na concentração dos jogadores antes de um jogo de futebol. E essa imersão pode gerar ótimos resultados.

Além de aproveitar o tempo para fazer pesquisas, repetir, repetir e repetir os argumentos orais, treinar o uso do tempo e praticar a elaboração de respostas a novas possíveis perguntas que poderão ser realizadas pelos juízes da competição, os alunos podem ainda se beneficiar da presença de várias equipes no mesmo local, e treinar com elas. É claro que, no fundo, todas estarão competindo entre si, mas deixar esse espírito de competição de lado e substituí-lo pela cooperação tende a trazer benefícios mútuos.

É uma boa prática, também, conhecer abordagens de outras equipes para os problemas do caso. Ler os memoriais de outros times, quando disponibilizados pela competição, ou assistir a outras rodadas são práticas muito comuns. Nesta etapa da preparação dificilmente será viável construir novos argumentos, mas é possível, ao menos, não ser inteiramente surpreendido com uma nova questão, e se prevenir sobre como respondê-la e discuti-la.

\section{O TREINAMENTO DOS ALUNOS: O CURSO DE PREPARAÇÃO PARA}




\section{MOOT COURTS}

Todas essas etapas são indispensáveis para a criação de uma boa equipe de moot court. Do conhecimento da competição aos últimos dias antes dela, há muito trabalho a ser feito. Mas não é só. Há uma série de habilidades que podem ser ensinadas aos alunos que participam de julgamentos simulados, uma preparação que antecede a competição. O curso de Preparação para moot court criado pela FGV Direito Rio buscou, de forma inovadora, investir nestas habilidades antes da seleção das equipes, formando assim um grupo qualificado de alunos interessados nas competições. Como?

Partiu-se de uma pergunta simples: em todas as competições, como já repetido, há duas etapas: escrita e oral. Quais as habilidades relevantes que podem auxiliar para a preparação de cada uma delas?

O primeiro passo é ensinar os alunos a formular textos argumentativos, a defender uma tese. Alunos em seus primeiros anos de faculdade muitas vezes tiveram pouco contato com petições, pareceres, documentos jurídicos. Aprender a defender um ponto de vista e convencer o leitor, a montar um argumento com início, meio e fim, ao invés de fazer uma simples exposição sobre o tema é essencial.

Simultaneamente, e pelas mesmas razões, os alunos vão aprendendo, com treino e orientação, a linguagem formal a ser utilizada em documentos jurídicos. Não se quer dizer, com isso, que devem ser usadas expressões latinas e termos incompreensíveis, mas sim uma linguagem mais técnica, acessível, porém própria de textos legais.

Ao aprender como defender uma posição os alunos devem aprender, também, como utilizar a jurisprudência de diferentes tribunais, e como buscá-la de forma eficiente, o que será útil por toda a vida profissional. Da mesma forma, é preciso aprender a usar de forma eficiente os casos encontrados: saber que não basta citá-los em notas de rodapé, ou utilizar trechos de decisões que repetem o conteúdo de artigos e citam lugares comuns, mas que é necessário relacionar o caso encontrado com o argumento que está sendo defendido. É necessário entender como chamar a atenção do leitor para o caso passado sem perder espaço excessivo para demonstrar a relevância daquele precedente.

O poder de síntese é, aliás, outro ensinamento indispensável e oriundo da prática que deve anteceder à preparação do aluno para um moot. É uma ótima prática, por exemplo, reler um argumento escrito em três páginas e reescrevê-lo para dizer o mesmo em três parágrafos. Exercícios como esse possibilitarão que estes alunos, no futuro, escrevam petições objetivas, que serão apreciadas com cuidado pelos magistrados.

Para a etapa oral, por sua vez, os ensinamentos vão muito além da oratória, embora ela constitua fator essencial. Perder o medo e a vergonha de falar em público, treinar gestos, postura, entonação e perder cacoetes de fala, como repetições de palavras, são habilidades indispensáveis para um mootie. Mas não suficientes.

Os alunos devem aprender a começar uma sustentação oral se apresentando, introduzindo claramente o tema que vai ser tratado, explicando em quantas partes será dividida sua apresentação, quais são elas, e de quais temas vão tratar. Essas técnicas facilitam a avaliação das apresentações pelos juízes. 
Devem aprender a usar o tempo: a se programar para deixar alguns minutos da apresentação para perguntas dos juízes, mas saber preenchê-los caso as perguntas não surjam; a resumir cada argumento em 30 segundos, para conseguir expô-los nas rodadas em que há tantas perguntas que alguns temas não conseguirão ser abordados.

Devem aprender - e isso é essencial - a retomar seu raciocínio depois de serem repetidamente interrompidos por perguntas de juízes ao longo de sua apresentação. E entender que as perguntas são um bom sinal: demonstram que os juízes estão atentos, que querem separar os bons participantes dos ótimos, e questionar os limites de cada competidor. Perguntas são positivas, e demonstram que o aluno pode ir muito além de um texto decorado.

Por outro lado, a prática ensina também aos alunos como agir quando ouvem uma pergunta que não sabem responder - o que acontecerá mais cedo ou mais tarde - como seguir adiante e manter a coerência e a lógica da apresentação mesmo depois dessa pequena falha.

Com o curso de preparação os alunos podem praticar também a forma com que devem se dirigir aos juízes, e se acostumar com a ideia de que podem usar tópicos para se organizar, contanto que não se percam no meio de dezenas de papéis de apoio. Aprendem, ainda, que não basta citar dezenas de casos. É preciso sempre conhecer cada um deles, ainda que resumidamente. E é preciso também conhecer a apresentação de todos os parceiros da equipe, e estar confortável para ser interrogado sobre qualquer aspecto do caso hipotético. Afinal, é isso que constitui, de fato, uma equipe: um trabalho conjunto, em que, ainda que haja uma divisão de tarefas, todos conhecem o produto final como um todo.

Mas como ensinar e treinar essas habilidades antes mesmo da escolha de uma equipe e do início do trabalho dos coaches?

A resposta é simples. São todas habilidades decorrentes da prática, do treino, pontos que precisam ser ressaltados para que os alunos passem a prestar atenção e mudem, aos poucos, sua forma de escrever e falar. Para isso não é necessário o caso da competição daquele ano, ou a dupla que irá participar daquela competição. Ao contrário: ensinar e treinar essas habilidades antes, para todos os alunos interessados, garante que, quando da seleção dos alunos, eles conhecerão melhor o cenário do que estão se propondo a fazer, e estarão mais qualificados para isso. E, o que é melhor, garante que, uma vez selecionada a equipe e publicado o caso, os alunos poderão se dedicar de maneira mais completa às pesquisas do caso específico, aos argumentos para aqueles fatos, já tendo assimilado habilidades que, em outro cenário, ainda precisariam aprender.

O curso pode trabalhar a partir de casos anteriores. A partir deles, os alunos podem elaborar um argumento e defendê-lo em sala de aula. As chaves, neste caso, são a prática e a repetição. Em cada aula, todos os alunos devem ter a oportunidade de fazer uma apresentação curta, de alguns minutos, com a possibilidade de serem interrompidos por perguntas. Essas apresentações devem ser gravada, para que eles possam revê-las, o que não é difícil em época de smartphones. E após cada apresentação os alunos devem ouvir comentários do professor e de seus colegas sobre como podem melhorar para a próxima semana. Na semana seguinte, tudo se repete. Aos poucos, os 
alunos ganham confiança, assimilando as críticas, e a melhora em algumas semanas é notável.

Com a preparação escrita não é diferente. A partir de um caso antigo, os alunos podem escrever pequenos textos, defendendo apenas um argumento, por exemplo, para ser entregue e devolvido com comentários. Devem, então, reescrever o mesmo texto, com atenção para os comentários anteriores. É uma simulação do que acontecerá no momento da elaboração dos memoriais, mas sem a mesma pressão, fazendo com que, aos poucos, o aluno aprenda como defender seu argumento de forma precisa, sintética e bem fundamentada.

O curso preparatório permite, ainda, que o professor explore casos anteriores das competições em que os alunos têm interesse, explique e tire dúvidas sobre como funcionam as competições e os tribunais que serão simulados. Faz com que os alunos analisem se querem, de fato, investir naquele tema, e demonstrem sua dedicação ao projeto, acostumando-se a dedicar, semanalmente, parte de seu tempo a ele.

A partir daí, será mais fácil fazer uma seleção de bons alunos interessados e formar boas equipes. Os alunos que não forem selecionados, por outro lado, poderão tentar novamente em anos posteriores. E, o que é mais importante, terão aprendido algumas práticas que os ajudarão em diversas áreas de suas vidas profissionais.

\section{CONCLUSÃO: POSSIBILIDADES TRANSFORMADORAS DA CRIAÇÃO DE UMA CULTURA DE MOOT COURTS}

A prática de incentivar e investir na participação regular em moot courts, de forma consistente, aprimorando as equipes e suas habilidades ao longo dos anos, vai além da experiência docente, do curso preparatório criado com esse propósito. Ela se constrói através de uma série de aprendizados decorrentes da atuação nestas competições ao longo dos anos, dentre os quais o curso de preparação é apenas um exemplo. Mas quais os benefícios adquiridos pelos alunos? Por que, afinal, investir em moot courts? O que os alunos ganham?

Em primeiro lugar, segurança. Alunos que saem de um moot court em que tiveram uma boa preparação e alcançaram bons resultados percebem a melhora em seu desempenho ao longo dos meses, veem a melhora de seus colegas de equipe e aprendem que podem enfrentar desafios complexos para conquistar seus objetivos. Saem, assim, muito mais confiantes em suas habilidades para fazer exposições ou defesas orais, falar em público, fazer sustentações. Afinal, já estiveram em uma situação em que estavam defendendo argumentos frente a uma plateia, com um grupo desconhecido de juízes que poderia fazer qualquer pergunta que lhes viesse à cabeça.

As habilidades aperfeiçoadas para a redação dos memoriais, por sua vez, com linha de raciocínio clara, fundamentada na jurisprudência dos tribunais, textos sintéticos, objetivos e bem elaborados, serão muito úteis para as petições iniciais, contestações e recursos que estes alunos ainda escreverão ao longo de sua vida jurídica.

Os alunos saem, ainda, como especialistas naquele campo. O integrante de uma equipe de moot court que simula perante a Corte Interamericana de Direitos Humanos conhecerá, com muito maior profundidade do que seus pares, o funcionamento do

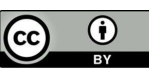


sistema interamericano, a jurisprudência da Corte e da Comissão Interamericanas, e terá uma clara vantagem competitiva caso deseje trabalhar nessa área. O mesmo ocorre com competições de arbitragem, de julgamentos penais, ou de qualquer área em que se escolha competir.

A atuação na área do moot, em verdade, se torna muito mais fácil não apenas pelo conhecimento do tema, mas também pela rede de contatos que é formada nestes eventos. Os moots reúnem um grupo de pessoas interessadas e especializadas naquela matéria, professores e advogados que poderão ser futuros empregadores daqueles alunos, bem como outros competidores que crescerão para assumirem papéis de destaque naquele campo. Os contatos criados nestas competições, assim, não devem ser subestimados.

Por fim, a prática de moot courts ensina aos alunos quais seus pontos fortes e fracos, a que precisarão se dedicar mais para se destacarem em suas profissões, e lhes mostra a importância do trabalho em equipe, ferramenta indispensável em qualquer profissão.

É uma experiência acadêmica única, que só pode ser integralmente compreendida por aqueles que já fizeram parte dela. A prática de investir em uma cultura de valorização de moot courts não é fácil, mas há muito a ganhar, seja para alunos, professores ou coaches. Que venham os moots! 